\title{
What do dogs (Canis familiaris) see? A review of vision in dogs and implications for cognition research
}

\author{
Sarah-Elizabeth Byosiere $^{1}$ (D) Philippe A. Chouinard ${ }^{1} \cdot$ Tiffani J. Howell $^{1}$. \\ Pauleen C. Bennett ${ }^{1}$
}

Published online: 15 November 2017

(C) Psychonomic Society, Inc. 2017

\begin{abstract}
Over the last 20 years, a large amount of research has been conducted in an attempt to uncover the cognitive abilities of the domestic dog. While substantial advancements have been made, progress has been impeded by the fact that little is known about how dogs visually perceive their external environment. It is imperative that future research determines more precisely canine visual processing capabilities, particularly considering the increasing number of studies assessing cognition via paradigms requiring vision. This review discusses current research on visual cognition and emphasizes the importance of understanding dog visual processing. We review several areas of vision research in domestic dogs, such as sensitivity to light, visual perspective, visual acuity, form perception, and color vision, with a focus on how these abilities may affect performance in cognition tasks. Additionally, we consider the immense diversity seen in dog morphology and explore ways in which these physical differences, particularly in facial morphology, may result in, or perhaps even be caused by, different visual processing capacities in dogs. Finally, we suggest future directions for research in dog vision and cognition.
\end{abstract}

Keywords Visual processing $\cdot$ Dog $\cdot$ Cognition . Morphology

In the last 20 years, researchers have discovered a variety of behaviors and abilities that make dogs an important model for studying cognition. This is largely a result of their unique

Sarah-Elizabeth Byosiere

s.byosiere@latrobe.edu.au

1 School of Psychology and Public Health, La Trobe University, P.O. Box 199, Bendigo, Victoria 3552, Australia social cognitive abilities (Hare \& Tomasello, 1999; Miklösi, Polgárdi, Topál, \& Csányi, 1998; Soproni, Miklósi, Topál, \& Csányi, 2001; Udell \& Wynne, 2008), and began when it was found that dogs outperform all other non-human animal species in locating hidden food based on human-given cues (Bräuer, Kaminski, Riedel, Call, \& Tomasello, 2006; Hare, Brown, Williamson, \& Tomasello, 2002; Kaminski, 2009). While a myriad of research has since been conducted with dogs, many of the findings are not without controversy.

Across cognition studies there appears to be unexplained variation in observed findings. For example, in studies of object permanence, it remains unclear whether or not dogs are capable of visible and invisible displacement tasks (e.g., Bell \& Fox, 1997; Collier-Baker, Davis, \& Suddendorf, 2004; Fiset, Beaulieu, \& Landry, 2002; Gagnon \& Dore, 1992; Gagnon \& Doré, 1994; H. C. Miller, Gipson, Vaughan, Rayburn-Reeves, \& Zentall, 2009). Additionally, in gestural communication studies, conflicting findings are often observed in performance in pointing and gaze cue tasks (e.g., Dorey, Udell, \& Wynne, 2010; Hare \& Tomasello, 2005; Soproni, Miklósi, Topál, \& Csányi, 2002; Tauzin, Csík, Kis, \& Topál, 2015; Udell, Dorey, \& Wynne, 2008; Virányi et al., 2008; Wynne, Udell, \& Lord, 2008). While these mixed findings in canine cognition studies may be due to a variety of reasons, below we highlight two that have often gone unrecognized.

First, little is known about vision in dogs. However, to date, the most common approach to assessing dog cognition is via visual tasks. In fact, approximately $74 \%$ of dog cognition studies use visual tasks (Bensky, Gosling, \& Sinn, 2013). On the one hand, this is not surprising, as many cognition tasks used in human and non-human animal (hereafter animal) research utilize experimental paradigms that are heavily reliant on vision. What is surprising is the lack of research on dog vision and visual perception, needed to justify the use of these 
visual paradigms, many of which require recognizing, or making distinctions between, certain visual details.

Second, dogs represent the most morphologically diverse species in existence (Hart, 1995; Wayne, 1986a, 1986b), with exceptional systematic variation between breeds (Wayne \& Ostrander, 2007). Dogs also differ behaviorally in systematic ways that reflect diverse selection pressures, now encoded genetically in different breeds. For example, sight-hound breeds were selected to hunt primarily by sight and chasing at speed, whereas terriers were predominantly used to hunt ground-dwelling vermin, using odors and a powerful physique suited to digging tenaciously until their quarry is unearthed. Considering sight-hounds and terriers differ in height, size, body type, facial morphology, and behavior, it is feasible to consider if these differences could be associated with, affect, or perhaps even be caused by, different visual processing capacities. Conceivably, selection for different visually-directed behaviors underpinned some of the differences in morphology that arose as breeds were developed.

This makes potential morphological differences in visual perception of enormous theoretical interest. It may also help to explain discordant experimental outcomes that appear, potentially due to the composition of the sample of dogs used in a given study. Individual differences in visual perception have been acknowledged, often in limitation sections of research articles as a possible reason for differences in observations, particularly when sample sizes are small. To our knowledge, however, formal assessments of these differences remain scarce (for a review, see Bensky et al., 2013).

As will be evident from this review, significant gaps exist in our understanding of fundamental visual perceptual capacities of dogs in general, and of morphologically distinct breed types more specifically. This makes it difficult to determine whether or not specific visual cognition tasks are appropriate for assessing canine cognition. Is it the case that testing conditions for some cognitive tasks are outside some or all dogs' perceptual capabilities? While the answer to this question is not known, the goal of this review is to provide an overview of dogs' visual system, visual perception, and morphology, to examine the effect these may have on canine cognition research, and to suggest areas where the need for additional research is urgent.

\section{Part 1: Understanding dogs' visual system}

A basic understanding of dog vision has been available for over two decades, with an extensive review being published by P. E. Miller and Murphy (1995). Advances in canine vision science since then have been limited, and this remains an excellent in-depth overview of many aspects of the dogs' visual system. However, in the last two decades, the amount of research conducted with dogs, and the way their cognitive skills are assessed, has drastically changed. For example, experiments now involve visual stimulus presentation (e.g., Pongrácz, Miklósi, Dóka, \& Csányi, 2003), and touchscreens (e.g., Range, Aust, Steurer, \& Huber, 2008), to name a few. Therefore, we begin this review with a brief overview of vision in dogs, specifically highlighting aspects of dog vision that may affect perception during modern visual cognition tasks.

\section{Fundamentals of dog vision}

While dogs appear to be visual generalists, with functional vision during both the day and night (Duke-Elder, 1958; Walls, 1942), they appear to be more scotopic than humans, meaning that they are highly adapted to function in dim light. In fact, they appear to have developed several ways of improving visual functioning across a variety of ambient light levels. The retina of the dog is largely composed of rod photoreceptor cells, which are extremely helpful in dim light as they can function in less intense light conditions (Kemp \& Jacobson, 1992). Only $3 \%$ of retinal cells in dogs are cone photoreceptor cells, which are primarily responsible for color vision (Peichl, 1992). This compares with roughly $5 \%$ in humans (Purves, Augustine, \& Fitzpatrick, 2001).

Although a foundational understanding of rod and cone photoreceptor cells in dogs is available, only recently have scientists furthered our knowledge of their precise distribution. Mowat et al. (2008) observed that the area centralis, a region typically centrally located in the retina, contains the maximal density of rod and cone photoreceptor cells in dogs. Even though cone photoreceptor cells are more numerous in the central portion of the retina (20\% of all receptors) (Koch \& Rubin, 1972; Parry, 1953; Peichl, 1992), the area centralis in dogs does not consist exclusively of cones as it does in humans (Mowat et al., 2008). These newer findings are consistent with older work, some of which is reviewed below, suggesting that dogs may be more adapted to dim light conditions and less sensitive to color perception than humans. If so, this would have clear implications for cognitive tests requiring color discrimination.

\section{Sensitivity to light}

While both dogs and humans utilize rod photoreceptor cells to function in dim light conditions, the rod photo pigment, rhodopsin, differs between the two species. Rhodopsin, a gprotein-coupled receptor, is highly sensitive to light and improves vision in dim light conditions. Dogs typically have a rhodopsin peak sensitivity to light wavelengths of 506510nm (Jacobs, Deegan, Crognale, \& Fenwick, 1993; Kemp \& Jacobson, 1992; Parkes, Aguirre, Rockey, \& Liebman, 1982), while humans have a peak sensitivity to slightly shorter wavelengths of $495 \mathrm{~nm}$ (Kraft, Schneeweis, \& Schnapf, 
1993). As the peak rhodopsin wavelength sensitivity hardly differs between dogs and humans, it appears that the dog's enhanced vision in dim light conditions may be due to other attributes (P. E. Miller \& Murphy, 1995). However, additional research is required to substantiate such claims.

One attribute that increases dogs' sensitivity in dim light conditions is the reflective tapetum lucidum. This superiorly located layer of tissue in the eye is a biologic reflector system commonly found in vertebrates (Ollivier et al., 2004), but not in humans. Typically, the tapetum lucidum offers lightsensitive retinal cells an additional opportunity for photonphotoreceptor stimulation by reflecting light, which has already passed through the retina, back through it a second time. This reflection enhances visual sensitivity in dim light conditions, but typically reduces the ability of the eye to observe details of an image due to increased scattering of light in the eye (Walls, 1942).

Perhaps surprisingly, there is variation in dogs' tapetum lucidum (Granar, Nilsson, \& Hamberg-Nyström, 2011; Lesiuk \& Braekevelt, 1983). A strain of laboratory beagles has been observed to have hereditary tapetal degeneration (Burns, Bellhorn, Impellizzeri, Aguirre, \& Laties, 1988) and, in a sample of $539 \mathrm{dogs}$, a tapetal area was completely present in only $70.3 \%$ of them, being completely absent in $1.9 \%$ (Granar et al., 2011). Generally, smaller sized breeds, like Papillons, Shetland Sheepdogs, Dachshunds, American Cocker Spaniels, Miniature Schnauzers, Miniature Poodles, Bichon Frisé/Havanais, and Cavalier King Charles Spaniels, have a smaller tapetal area, while larger dogs, like Border Collies, Leonbergers, Samoyeds, Golden Retrievers, and English Springer Spaniels, typically have a full-sized tapetal area (Granar et al., 2011). Labrador Retrievers have smaller than expected average tapetal size because there appears to be increased variation within the breed. Specifically, a large proportion of Labradors lack a tapetal area. Thus, it appears that the size of the tapetal area depends largely on breed and body size, but that marked variation may also exist within a breed.

Since the main function of the tapetum lucidum is to facilitate detection of small amounts of light, perhaps dogs without a tapetum lucidum are worse at discriminating between light conditions. We were unable to uncover evidence for such an effect, and the previous review on vision in dogs claimed that no functional differences had been reported (P. E. Miller \& Murphy, 1995). Regardless, as this kind of variability within a species is uncommon, it should be investigated further using modern, technologically advanced equipment and techniques. We recommend future research attempt to evaluate the effects of tapetal-area differences, or develop a method for easily observing such differences so that researchers can be aware of potential physiological differences within their sample.

Finally, as dogs are sensitive to a variety of light conditions, this can affect their recovery from exposure to bright light. The phenomenon of photo bleaching occurs when photo pigment becomes almost transparent following exposure to light, after which it must regenerate to regain pigmentation when in the dark. The regeneration from rhodopsin's photo bleaching effects is longer in dogs (over an hour) than in humans (approximately $30 \mathrm{~min}$ ). This means that when a dog and a human come inside after having been outside, the recovery time from the photo bleaching effect is twice as long in dogs as it is in humans. Because abrupt changes in light conditions could more drastically affect dogs than humans, this should be considered when bringing dogs from bright outdoor environments directly into indoor laboratories for cognitive testing.

\section{Brightness discrimination}

As dogs appear to have evolved as visual generalists, it may be assumed that their sensitivity to differences in brightness would be quite good. However, two relevant studies provide conflicting reports. Stone (1921) observed relatively low brightness discrimination thresholds for two fox terriers, comparable with thresholds observed in humans. By calculating the smallest difference between two stimuli that the dogs could detect, Stone (1921) determined Weber fractions of 0.12 and 0.10 , a result quite comparable to the 0.11 observed in humans (Griebel \& Schmid, 1992). However, he only assessed the dogs on one standard brightness intensity, a potential limitation as psychophysical studies on humans demonstrate that brightness discrimination thresholds decrease with increasing light intensity (Craik, 1938)

More recently, Pretterer, Bubna-Littitz, Windischbauer, Gabler, and Griebel (2004) observed that brightness discrimination was about two times worse in $\operatorname{dogs}$ than it is in humans, with reported Weber fractions of 0.22 and 0.27 for three subjects, a German Shepherd and two Belgian Shepherds. This result suggests a relatively high brightness discrimination threshold for dogs compared to Stone (1921). It has been previously suggested (Scholtyssek, Kelber, \& Dehnhardt, 2008) that the high threshold observed by Pretterer et al. (2004) is likely a result of the experimental methods and may underestimate the brightness discrimination capabilities of dogs. In the experiment, dogs were required to discriminate between stimuli of various intensities that were $1.1 \mathrm{~m}$ apart, a reasonably large distance that may have affected the subject's choices and, consequently, the threshold observed. Additional research is required to evaluate the findings of these two studies.

\section{Visual acuity and spatial resolution}

Visual acuity refers to the clarity of vision and is dependent on optical and neural mechanisms (e.g., eye structure, the health of the eye, the brain's interpretation). While dogs' visual acuity is difficult to measure, it is typically estimated to be 
considerably worse than humans'. Based on a variety of studies employing different methods, such as behavioral testing, measurement of visually evoked cortical potentials, pattern electroretinography, and optokinetic responses, P. E. Miller and Murphy (1995) estimated the visual acuity of a typical dog to be 20/75. This value suggests that, from 20 feet away, a dog could perceive an object that a person with normal vision could differentiate from 75 feet away.

A lack of visual acuity in dogs is not surprising, as there is likely a trade-off that exists in dog vision. Considering the physiology of the dog eye discussed above, and the dim light conditions to which it is adapted, dogs may be more sensitive to light at the expense of being able to discriminate smaller details. Whether the exact value of 20/75 reported by P. E. Miller and Murphy (1995) is correct or not, however, has proved difficult to determine.

Murphy, Mutti, Zadnik, and Ver Hoeve (1997) assessed visual acuity in three young adult Beagles using sweep visual-evoked potentials. This method allows for visual acuity estimates by measuring the cortical response to a sequence of gratings of increasing spatial frequency. Visual acuity estimates were between 20/45 and 20/85. More recently, a behavioral assessment of visual acuity has been conducted by Tanaka, Ikeuchi, Mitani, Eguchi, and Uetake (2000). These authors reported visual acuity estimates of 20/60 to 20/85 in three Shiba dogs.

Even taking into account the fact that differences in acuity estimates are also highly variable in other species, with those obtained through behavioral investigations often indicating lower acuity than electrophysiological acuity measures (Murphy et al., 1997), these disparate estimates suggest that further work is required. It would be of great interest to know whether all dogs have similar levels of visual acuity or vary systematically according to breed, morphology, or other factors. Such research would allow cognition researchers to more accurately create appropriately sized stimuli and viewing distances, such that dogs would be capable of perceiving them.

\section{Depth perception}

Binocular overlap refers to the overlapping portion of a visual scene that is viewed by both eyes. Due to our forward facing eyes, and relatively unobtrusive noses, humans have a degree of binocular overlap of roughly $140^{\circ}$ (Walls, 1942). In dogs, various estimates of binocular overlap exist and these vary based on the immense variation in facial morphology types as well as the methodology used to calculate the estimates. P. E. Miller and Murphy (1995) report that, in behavioral studies, binocular overlap has been estimated to be roughly $30-60^{\circ}$. However, it can be anywhere from $35^{\circ}$ to $40^{\circ}$ when calculated based on ganglion cell density (Peichl, 1992), and 80-116 when calculated based on optical considerations (Duke-Elder, 1958; Walls, 1942).
Depth perception, or stereopsis, represents the visual ability to perceive the world in three dimensions (3-D) and is enhanced in regions where both eyes have overlapping fields of view. This occurs when both eyes view the external world from different vantage points and the information is merged to create a single image. It is this fusion of image that allows the eye to accurately perceive depth (Bishop, 1987). In a visual cliff experiment, young puppies demonstrated outstanding monocular (single eye) and binocular depth perception (Walk \& Gibson, 1961). Considering the canine eye does not completely develop until they are juveniles or young adults (a few months of age), P. E. Miller and Murphy (1995) suggested that adult dogs likely have even better visual depth perception. Additional research is needed to substantiate these claims, however, as studies of retinal ganglion cell topography suggest that depth perception in dogs may be impaired. Dogs lack alpha, also termed "Y," ganglion cells, in both the right and left portions of the $15^{\circ}$ of the peripheral binocular overlap (Peichl, 1992). Thus, it is possible that there is a smaller area of binocular overlap where the retina perceives high quality depth perception. Additional research is clearly required to confirm available information, and also to determine if depth perception varies systematically by breed.

\section{Color vision}

The dog's ability to distinguish different colors remains controversial. Humans have three types of cone photoreceptor cells (long-wave (red), medium-wave (green), and shortwave (blue), at spectral peaks of $558 \mathrm{~nm}, 531 \mathrm{~nm}$, and 419 $\mathrm{nm}$, respectively). Dogs have only two, which almost identically correspond to short-wave and long-wave sensitivities (blue at a spectral peak of $555 \mathrm{~nm}$ and yellow at $429 \mathrm{~nm}$ ) (Jacobs et al., 1993; Neitz, Geist, \& Jacobs, 1989). This has been used to suggest that dogs may be unable to perceive differences between green, yellow, and red color cues. Accordingly, early studies suggested dogs lacked good color vision (Neitz et al., 1989). However, there is some even older evidence that suggests dogs may be able to perceive these colors (e.g., red and green) even without possessing the cone photoreceptor cells believed to be responsible for this ability (Rosengren, 1969). More research is needed to understand the extent to which dogs perceive color, and how similar dog color perception is to that of non-color-blind humans.

Even with this limitation in mind, dogs appear to be attentive to the colors they can perceive. Two Shiba dogs were able to appropriately identify a positive stimulus (red, blue, or green compared to grey) in a two-choice discrimination task, where the light intensity on the cards was 450-500 lux (Tanaka, Watanabe, Eguchi, \& Yoshimoto, 2000). The authors of this study suggested that color vision is relatively well developed, considering the dogs were able to discriminate between all three primary colors and grey. Another study 
showed that, under natural photopic lighting conditions, dogs might preferentially use color over brightness cues, when presented with yellow and blue stimuli in a discrimination task (Kasparson, Badridze, \& Maximov, 2013). Eight dogs were observed to use color over brightness cues when discriminating and recognizing visual objects (Kasparson et al., 2013). These findings suggest that color may be a fundamental feature of visual objects as perceived by dogs. However, additional research is needed to assess their performance in various light conditions.

In addition to their preference for color cues, it appears that dogs may have a capacity to perceive ultraviolet light (Douglas \& Jeffery, 2014). In a cross-species assessment of ultraviolet (UV) sensitivity in mammalian eyes, dogs were identified to have lenses transmitting significant amounts of UV rays (335 nm). This suggests that even though dogs do not have a specific UV visual pigment, they may be sensitive to ultraviolet light (Douglas \& Jeffery, 2014). If this is the case, cognition researchers must begin to determine the UV light levels that dogs can perceive, and consider the effects this may have on the stimuli and conditions in which they are being assessed.

Finally, there is evidence to suggest that dogs may have a magnetic sense associated with their visual system. A recent study observed the presence of cryptochrome 1, a flavoprotein located in the canine eye that is sensitive to blue light. Additionally, it is involved in responding to light-dependent magnetic orientation based on the earth's magnetic field (Nießner et al., 2016). These authors suggest that this does not likely act as an additional pigment for the perception of color, but instead likely functions to perceive the earth's magnetic field.

\section{Sensitivity to monitors}

Sensitivity to flickering lights has become relevant in the study of dog cognition due to the frequent use of screenpresented stimuli in cognition tests. The flicker fusion rate is the point at which rapidly flickering light appears to meld into a constantly illuminated light. This is important when presenting videos as these rely on presenting a rapid succession of static images. If the frame rate, in Hertz $(\mathrm{Hz})$, is below the threshold of sensitivity, the flicker will be viewable and the film will appear jerky. Therefore, studying flicker fusion rates offers insight into the functional qualities of dog visuoperception.

Originally, electroretinographic studies of anesthetized dogs suggested they could detect flickering up to a maximum of approximately $20 \mathrm{~Hz}$ (Gustavo Aguirre, 1978; GD Aguirre \& Rubin, 1975). However, behavioral paradigms using unanesthetized dogs suggest a more sensitive flicker detection, approximately 70-80 Hz. More recently, Healy, McNally, Ruxton, Cooper, and Jackson (2013) observed flicker fusion frequencies to be $80 \mathrm{~Hz}$ in dogs compared to $60 \mathrm{~Hz}$ in humans. This is potentially a major problem for dog cognition studies, as these findings suggest that dogs are more sensitive to flicker than humans, and more sensitive than could easily be accommodated by some screens currently in use. What appears as a fluidly moving video image to humans may appear as a flickering image to dogs, making it difficult to determine if their performance on relevant tests is a genuine indicator of their cognitive abilities.

Furthermore, it is possible that the presentation of static images on a monitor is also affected by dogs' greater sensitivity to flicker-fusion rates. Refresh rates, the number of times in a second that a display renews an onscreen image, may also be perceived differently by dogs than by humans. For example, cathode ray tube (CRT) monitors are typically set to present at $60-70 \mathrm{~Hz}$ for humans, in order to avoid viewing of flickering. While CRT monitors are no longer common, they may be used in some research contexts depending on the aims of the study. For example, CRT monitors tend to maintain a more stable brightness than modern liquid-crystal display (LCD) monitors. LCD monitors typically exhibit no refresh rate-induced flicker, and are commonly set to present at $60 \mathrm{~Hz}$ (although given technological advancements there is increased variation in this value). Unlike CRT monitors, pixels on LCD monitors do not necessarily flash on/off between frames. Therefore, the flicker effect often observed on older screens may no longer be a potential confound as long as the flicker-fusion rate is above the threshold observed in dogs. Considering these physiological differences (compared to humans) it is important to utilize proper technological tools, as well as to be aware of how differences in physiology may indirectly affect experimental outcomes.

\section{Part 1 conclusions}

In summary, while the visual system of dogs may be considered to be worse than that of humans in many ways (P. E. Miller \& Murphy, 1995), it is evident from our review that, in some ways, their vision is superior, or at least different. It seems that the visual acuity and color perception capabilities of domestic dogs are less sensitive than those observed in humans, but the observed flicker-fusion rate, and their ability to function in dim light, surpass those of human capacities. Of most relevance here is that many aspects of dog vision remain substantially understudied. Moreover, many studies have used extremely small sample sizes, often comprising a single breed, and, as a result, individual, breed, and morphological differences have rarely been considered (for a review see Arden, Bensky, \& Adams, 2016). 


\section{Part 2: Visual perception in dogs}

When perceiving visual stimuli, the brain processes retinal information, allowing humans and animals to interpret the external world and act upon it (Haber \& Hershenson, 1973). Visual perception reflects the brain's interpretation of the physical properties of an object, but may not always accurately reflect the physical properties themselves. For instance, the mind may adapt the information due to preconceptions based on experience and neurological connections, thereby permitting the viewer to successfully navigate the world in a more "adaptive" way (Kandel \& Schwartz, 2000). But how do we, and other species, perceive the world, and which mechanisms are used to extract meaning from a visual scene? The question is far from simple, as many different physiological and neurological components are involved in visual processing. Currently, Bayesian explanations for visual perception suggest that the brain creates an optimal combination of incoming sensory information and prior knowledge in order to make sense of an organism's surroundings (Knill \& Pouget, 2004).

Recently, researchers have attempted to replicate the way in which dogs perceive visual scenes. Pongrácz, Ujvári, Faragó, Miklósi, and Péter (2017) altered images according to hypothesized dog visual perceptive conditions, producing a dichromatic scene with poor resolution and low brightness. The researchers noted that, when a scene is altered in this way, humans who perceive the scene perform poorly at distinguishing certain contextual information relayed in the image. While these findings are intriguing, they primarily highlight that, when given blurry and less colorful photographs, humans find it more difficult to draw out relevant information. What has yet to be determined is whether the criteria and the perceptive conditions imposed on the images are, in fact, an accurate representation of what dogs actually see, as well as how they process and utilize visual information. Given the lack of research currently available on the fundamentals of dog vision, drawing additional conclusions seems unwarranted. Below we discuss research that has assessed visual perception in dogs, in an attempt to better understand how dogs perceive incoming visual information.

\section{Visual discrimination and form perception}

Visual discrimination abilities of domestic dogs have traditionally been tested using two-choice discrimination paradigms. These typically require extensive training. From these studies, it has been observed that dogs can easily learn to discriminate between stimuli on the basis of form. For example, dogs can discriminate between different objects (Milgram, Head, Weiner, \& Thomas, 1994), black/white stimuli (e.g., Araujo, Chan, Winka, Seymour, \& Milgram, 2004; Burman et al., 2011; Frank, 2011), and between objects of different sizes (Byosiere et al., 2016; Milgram et al., 2004; Tapp et al., 2004).

Research has also demonstrated that dogs are able to discriminate between differences in the quantities of stimuli displayed. Quantity discrimination tasks, where subjects are presented with food rewards of different sizes, have found that dogs preferentially select the larger quantity of two rewards. However, performance varies as the ratio between quantities is reduced (Baker, Morath, Rodzon, \& Jordan, 2012; Petrazzini \& Wynne, 2016; Ward \& Smuts, 2007). While mixed findings have been observed, it appears that dogs are only capable of discriminating quite large (e.g., 5 vs. 10) rather than quite small (e.g., 2 vs. 3) quantitative differences.

More recently, Byosiere et al. (in prep.) assessed visual discrimination capabilities in Lagotto Romagnolo dogs by assessing their size sensitivity thresholds. All subjects successfully discriminated between circles that differed in diameter by $20 \%$ (42 pixels, approximately 12.6 $\mathrm{mm})$. However, variation in sensitivity was observed; four of the eight dogs were able to discriminate between circles $10 \%$ different in diameter ( 21 pixels, approximately $6.3 \mathrm{~mm}$ ) but none were able to discriminate circles $5 \%$ different in diameter (10 pixels, approximately $3 \mathrm{~mm}$ ). These findings are comparable to those observed in primate species; humans, chimpanzees, bonobos, olive baboons, and long-tailed macaques have all demonstrated successful discrimination of 3-D cubes varying in volume by $20 \%$ (Schmitt, Kröger, Zinner, Call, \& Fischer, 2013). Furthermore, absolute size of the stimuli appears to affect performance in dogs. While using identical percent size differences across stimuli of varying absolute size, dogs were more successful at discriminating between stimuli that were larger than stimuli that were smaller. Considering dog's diminished visual acuity, it is possible that these findings further reflect a difficulty in discriminating fine details.

In addition to perceiving size differences, it has also been reported that dogs can perceive and discriminate shapes (Duke-Elder, 1958). Karn and Munn (1932) observed that dogs quickly learned to discriminate between horizontal and vertical lines; however, they learned more slowly when discriminating between upright and inverted triangles. Interestingly, once the dogs learned the discrimination task they appeared to be able to generalize their performance to triangles of decreasing size. While it remains unclear how the dogs discriminated between stimuli, perhaps due to the orientation of the triangle rather than the shape, they appeared to discriminate based on cues presented in the lower portion of the patterns.

Byosiere et al. (2017a) evaluated if dogs could generalize a previously learned rule to novel stimuli. After learning a twochoice size discrimination task, where selecting the larger 
circle stimulus over the smaller resulted in a reward (or vice versa), the subjects were presented with various novel shapes. The results demonstrated that the dogs were capable of generalizing the previously learned size discrimination rule to novel situations; however, there were differences in the dogs' generalization capabilities. Specifically, dogs were highly successful at generalizing their "rule" to ovals, squares, rectangles, diamonds, triangles, and stars, but not to vertical or horizontal lines. These findings suggest that perhaps lines are perceived differently from the other shapes, possibly due to differences in overall size.

Taken together, these findings suggest that, given appropriate training, dogs can discriminate between stimuli based on shape and size. However, how they perceive these differences, and the extent to which this is similar to humans, remains unknown. Therefore, additional, more complex assessments of psychonomic phenomena have been conducted, which we discuss in detail below.

\section{Global/local precedence}

Many visual scenes contain both global (e.g., a bouquet of flowers) and local (e.g., individual flowers within the bouquet) features and, in humans and other animals, there is division of labor within the visual system for processing these features (Laycock, Crewther, \& Crewther, 2007). Certain species, such as pigeons, demonstrate a preference for identifying local features (Cavoto \& Cook, 2001). In contrast, Navon (1977) observed that humans identify global (e.g., the bouquet) faster than local (e.g., the individual flowers) features using a task in which a large letter is made up of smaller letters (see Fig. 1). Typically, humans more quickly recognize the larger global letter depicted in the figure (i.e., the $\mathrm{H}$ ) than the multiple smaller local letters (i.e., the $\mathrm{X}$ ).

One study has assessed global and local processing in dogs. Using two dimensional (2-D) hierarchical compound images created using letters and shapes, Pitteri, Mongillo, Carnier, and Marinelli (2014) trained dogs to identify a consistent stimulus, either an "O" made up of circles or an " $\mathrm{X}$ " made up of $\mathrm{Xs}$, in a discrimination task. After an extensive training process, dogs were presented with two incongruent stimuli in a test phase. One displayed the global element they were trained on, and the other displayed a local element they had never seen (depending on the training stimulus, an "O" made up of "Xs" or an "X" made up of "Os"). The researchers observed that there was a trend for dogs to process stimuli in a globally oriented fashion, although there appeared to be much individual variation (Pitteri, Mongillo, Carnier, \& Marinelli, 2014). A re-test of the same dogs after 2 years suggested that individual global/local preferences are stable over time and that there was still a trend for an overall global bias in dogs (Mongillo, Pitteri, Sambugaro, Carnier, \& Marinelli, 2016).

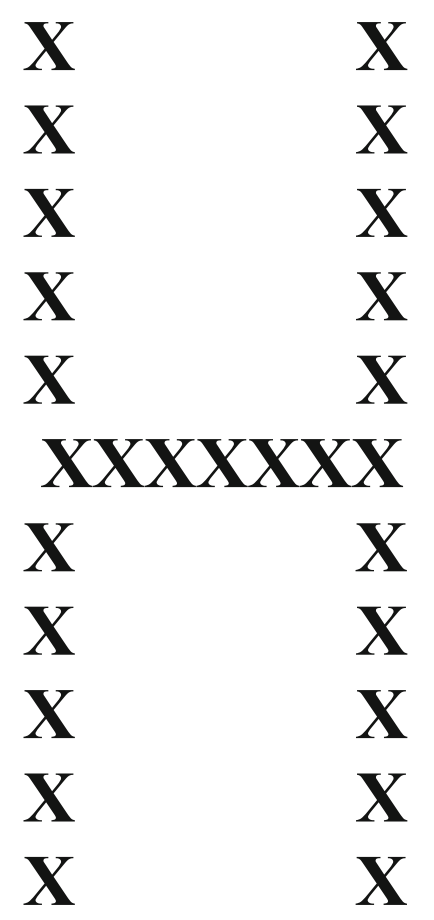

Fig. 1 Example of a Navon figure where the global and local features are incongruent. The global feature is represented by the letter " $\mathrm{H}$ " and the local feature is represented by the letter " $\mathrm{X}$ "

It is clear from a number of experiments in humans, however, that global processing should not be considered a singular construct, invoked by the same cognitive operations across all types of global tasks. Rather, it is an umbrella term denoting multiple independent mechanisms (Chouinard, Noulty, Sperandio, \& Landry, 2013; Chouinard, Unwin, Landry, \& Sperandio, 2016). Specifically, it is possible to demonstrate local precedence on some tasks, while demonstrating an overall global precedence across a variety of tasks.

Furthermore, considering dogs have reduced visual acuity, is the task an appropriate assessment of precedence? In Pitteri, Mongillo, Carnier, and Marinelli (2014), the dogs were positioned $1.3 \mathrm{~m}$ away from the stimuli and, while the exact distance is not specified in the manuscript, the apparatus was 1.4 $\mathrm{m}$ wide, with the edge of each stimulus $14 \mathrm{~cm}$ from the edge. Based on the evidence discussed in Part 1, it seems likely that dogs are unable to perceive small details from such a distance. If dogs do not have the capacity to process detail, they could not behave in a way demonstrative of local precedence, or detail processing. To fully determine whether dogs are "global processors," additional precedence tasks should be conducted and the results compared.

These results again highlight the need for more foundational research, such as development of reliable visual acuity measures, to assess whether such large distances between stimuli, or between the dog and the stimuli, are appropriate. In the absence of such instruments, one way forward might be to assess dogs' performance on other 
tasks of visual perception, such as tests assessing susceptibility to geometric illusions.

\section{Visual perception and misperception}

One method used to study perception is assessment of misperception. Geometric illusions represent misperceptions of physical realities in the external world (Gregory, 2015). Under experimental circumstances, the induced illusion is the result of mechanisms that are normally helpful for seeing the external world in the most adaptive way, but which trick the brain into seeing something different by correcting when a correction is not necessary.

To our knowledge, three studies have assessed geometric illusion susceptibility in domestic dogs (Byosiere et al., 2016; Byosiere et al. 2017b; Miletto Petrazzini, Bisazza, \& Agrillo, 2016) (see Fig. 2 for detailed descriptions of the illusions assessed). Using a two-choice size discrimination task, Byosiere et al. (2016) trained eight Lagotto Romagnolo dogs to indicate the larger (or for some dogs smaller) stimulus. After an extensive training process, the dogs were presented with control and illusory stimuli and had an opportunity to nose-touch the stimulus perceived as being larger or smaller. They found that dogs perceived two different versions of the Ebbinghaus-Titchener illusion in a manner opposite to the direction in which humans and most other animals perceive the illusion. These findings suggest that dogs perceptually rescale the target circles in the display so that they appear more like the other inducer circles. In the Delboeuf illusion, thought to be similar to the Ebbinghaus-Titchener illusion in terms of its underlying mechanisms (Sherman \& Chouinard, 2016), both Byosiere et al. (2016) and Miletto Petrazzini et al. (2016) found that dogs were not susceptible (Fig. 2). However, certain individual dogs did demonstrate susceptibility, once again in the opposite direction to that observed in humans.

More recently, Byosiere et al. (2017) assessed canine susceptibility to the Ponzo illusion in four varying presentations

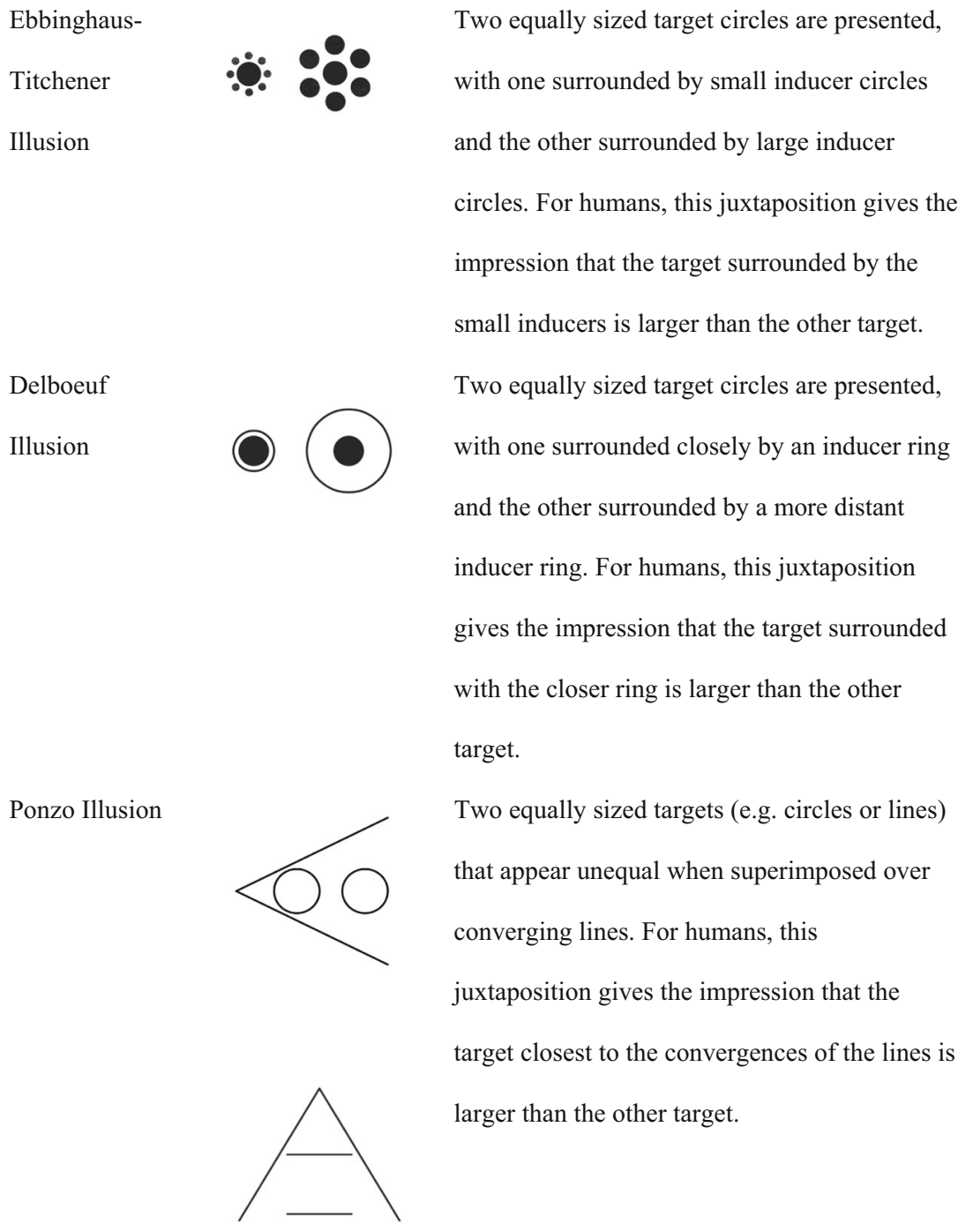

Ebbinghaus-

Titchene

and the other surrounded by large inducer

circles. For humans, this juxtaposition gives the

impression that the target surrounded by the

\section{Delboeu \\ Illusion}

Fig. 2 Schematic depictions and explanations of the Ebbinghaus-Titchener, Delboeuf, and Ponzo illusions 
(for an example of the Ponzo illusion, see Fig. 2). While the dogs demonstrated above-chance performance as a group in one presentation (56\%), no individual dog performed significantly above chance. In a re-test of the same presentation, and in two different presentations of the same illusion, no significant results were observed at the group level, although one or more dogs did demonstrate a small but significant effect (some in the same direction and others in the opposite direction to humans).

Taken together, then, there is limited evidence for dogs' susceptibility to the Ponzo illusion. While this may be due to their poor visual acuity and spatial resolution, we believe these findings could also be due to the way the stimuli were presented. Stimuli in the study were presented on a horizontal (landscape) plane. However, in humans, vertically (portrait)presented stimuli, where the apex is at the top, produce greater perceived depth and size than stimuli presented in any other orientation (R. J. Miller, 1997). Therefore, one potential explanation for these findings is that the horizontally presented stimuli may not have induced the Ponzo illusion in dogs, due to the fact that the illusion may have been weak. Furthermore, it is currently unknown whether or not dogs perceive the minimum size difference required in humans in order to perceive the Ponzo illusion. Additional research is required to address these issues.

These unexpected observations of canine illusion susceptibility have implications for theoretical explanations of underlying visual processing mechanisms. Seeing as most animals tested previously have demonstrated susceptibility in the same direction as humans (for a review, see Feng, Chouinard, Howell, \& Bennett, 2016), it is possible that the mechanisms underlying perception of illusory stimuli differ across species, leading only some to experience the illusion. Additionally, marked individual differences in illusion susceptibility were observed. It may be that in these instances a difference in individual visual acuity would explain the variation across subjects, but other explanations may also exist. Future research should attempt to assess illusion susceptibility across a variety of different dog breeds, as well as across different stimulus presentations, in order to provide additional evidence for these findings. Additionally, other psychonomic assessments of perception should be conducted in order to further understanding of the mechanisms underlying visual processing in dogs. If dogs do, in fact, process visual stimuli differently from humans, certain cognitive assessments may not appropriate, as they may not induce the hypothesized effect.

\section{Face processing}

In recent years, the majority of research in form perception has focused specifically on face processing. Dogs have been tested in various experimental paradigms, where they are asked to look at images of dog and human faces (e.g., Huber, Racca,
Scaf, Virányi, \& Range, 2013; Pitteri, Mongillo, Carnier, Marinelli, \& Huber, 2014; Racca, Guo, Meints, \& Mills, 2012). Outcomes from these paradigms suggest that dogs are able to differentiate familiar and unfamiliar faces presented as 2-D representations. These abilities even extend to obscured faces, where only certain areas of the face are shown. Racca et al. (2012) attempted to address whether dogs were able to distinguish between different human emotional expressions; however, the results were inconclusive. While they observed differential gaze biases depending on whether a friendly or threatening expression of a dog was shown, there was no such difference for human stimuli.

Nagasawa, Murai, Mogi, and Kikusui (2011) addressed a similar question: whether dogs could first learn to distinguish between smiling and neutral images of their owner and then transfer the ability to novel stimuli of unfamiliar humans. While the dogs were able to choose the owner's smiling face significantly above chance, their success rate was significantly lower when presented with an unfamiliar face. Not only has this research found that dogs can distinguish differences in human faces, but also that dogs can successfully discriminate dog faces from non-dog faces (Autier-Dérian, Deputte, Chalvet-Monfray, Coulon, \& Mounier, 2013), with a preference for facial images of conspecifics over human faces, toys, and alphabetic characters (Somppi, Törnqvist, Hänninen, Krause, \& Vainio, 2012).

Taken together, these findings suggest that dogs can process visual information cognitively at quite sophisticated levels, and raise questions about what kinds of cognitive strategies they use for this purpose. However, it should be noted that these studies assess quite complex processing abilities without first assessing foundational visual processing components. For example, many of these studies make the assumption that dogs visually perceive 2-D stimuli in much the same way as humans. The photographic presentations used are often large and not life-size, highlighting potential confounds such as the fact that these stimuli may not be perceived identically to actual 3-D human faces. Furthermore, considering dogs have reduced visual acuity, it is possible that small differences in emotional expression may not actually be perceived. Future research should first establish whether or not dogs process basic 2-D stimuli in the same way as 3-D stimuli before making broader generalizations about dog social cognitive abilities (for a case study on iconic representation in dogs see Kaminski, Tempelmann, Call, \& Tomasello, 2009).

\section{Part 2 conclusions}

In summary, many unique and interesting studies have been conducted on visual perception in dogs. While these studies shed light on how dogs perceive their external environment, many are affected by potential confounds that exist primarily due to a lack of fundamental vision research in dogs. These 
confounds make it extremely difficult to disentangle actual results from physiological limitations and may result in inappropriate conclusions. Furthermore, due to the extensive training process required in many of these paradigms, subject numbers are often small, meaning that assessing individual, breed, and morphological differences is often impossible. Due to the marked variation observed in dog morphology, it seems urgent to consider whether such differences may affect visual perception.

\section{Part 3: Morphological variation and its effects on eye structure and visual perception}

Neurobiological investigation suggests there are similarities in visual systems across vertebrates (Lamb, Collin, \& Pugh, 2007) as well as in the neural circuitry underlying vision in humans, non-human primates, and other mammals (Masland \& Martin, 2007). However, it is also clear that evolutionary pressures have led to differences in perceptual processes (Feng et al., 2016; Lamb et al., 2007). This is largely due to the fact that different species have different physiological features and functions, likely specialized to be adaptive for a given environment. Thus, while the same information that enters the eye may be available, it may be processed and interpreted differently by different species. Even the most precise descriptions of physiological and neurological processes underlying vision in a species may not provide a reliable representation of their visual processing capacities. Behavioral data are required to substantiate any conclusions drawn about the subjective visual experience of animals.

As discussed above, dogs represent an extremely variable species in terms of their physical appearance and behavior (Hart, 1995; Wayne, 1986a, 1986b). Reports from the American Kennel Club and the International Cynologic Federation indicate that approximately 400-500 dog breeds are currently registered. These breeds differ in many ways, such as size, weight, color, hair type, and length, ear and tail positions, body and facial shape. Considering this immense variation in morphology, it seems logical to contemplate whether even simple differences, such as height, could affect individual visual experiences (Fig. 3).

Furthermore, in dogs, varying facial morphologies exist, which further complicates interpretation of even the most basic physiologic measures assessing perception. For example, in brachycephalic breeds, the eye position is often more laterally directed than in dolichocephalic breeds (Fig. 4). Therefore, one would expect differences in the amount of binocular overlap, based on differences in eye-position, as well as the presence or absence of a muzzle obstructing the field of view (Evans \& De Lahunta, 2013). Accordingly, Kerswell, Butler, Bennett, and Hemsworth (2010) demonstrated that variation in morphological features affected communication in young dogs. Specifically, communicative social signals may be used differently depending on whether or not they are performed by a dog with a short or long snout. Additionally, it has been observed that larger dogs tend to perform better than smaller dogs when following human gestural pointing cues (Helton \& Helton, 2010). While a metaanalysis assessing response to human cues found no effect of breed (Dorey, Udell, \& Wynne, 2009), this may be partly because only a limited number of breeds have been included in available studies.

These studies suggest that morphological variation may affect outcome in performance, and it appears that, in dogs at least, this diversity may also affect visual processing (McGreevy, Grassi, \& Harman, 2003; Roberts, McGreevy, \& Valenzuela, 2010). McGreevy et al. (2003) observed that, while dog eye size is variable, it is strongly correlated with skull dimension. In addition, certain morphological variations, such as nose length and face shape, appear to affect eye structure. Even the total number of retinal ganglion cells appears to correlate with skull measurements and eye size. Perhaps most interesting is the finding that retinal ganglion cell distribution is highly variable and correlated with nose length. In some dogs, retinal ganglion cells were concentrated in a horizontal visual streak across the retina, which presumably provides more sensitivity to movement along a horizontal field of view. In others, they were concentrated in a strong area centralis, with virtually no streak being evident. Dogs with longer noses had obvious visual streaks, but those with short noses, such as pugs, had virtually no visual streak. Roberts et al. (2010) later observed that human selection for diversity in domestic dogs' body shape and size seems also to have resulted in artificial human selection pressures affecting the organization of the dog's brain.

However, do such differences affect the way in which dogs visually process their external environment? Gácsi, McGreevy, Kara, and Miklósi (2009) observed that, while dogs, regardless of breed group, appeared to be successful in a human gestural communication task, brachycephalic dogs, with flat faces and more forward-facing eyes, were significantly better in using the human pointing gesture than dolichocephalic dogs, with longer noses. These authors suggested that morphological characteristics might be indirectly associated with performance in cognition tasks, due to differences in visual processing.

Considering the drastic variation in size, body type, facial morphology, and behavior, it seems possible that such differences could be associated with, affect, or perhaps even be caused by different visual processing capacities. Perhaps selection for different visually directed behaviors underpinned some of the differences in morphology that arose as breeds were developed. The old adage of form following function may apply here; dogs may have been selected because of 

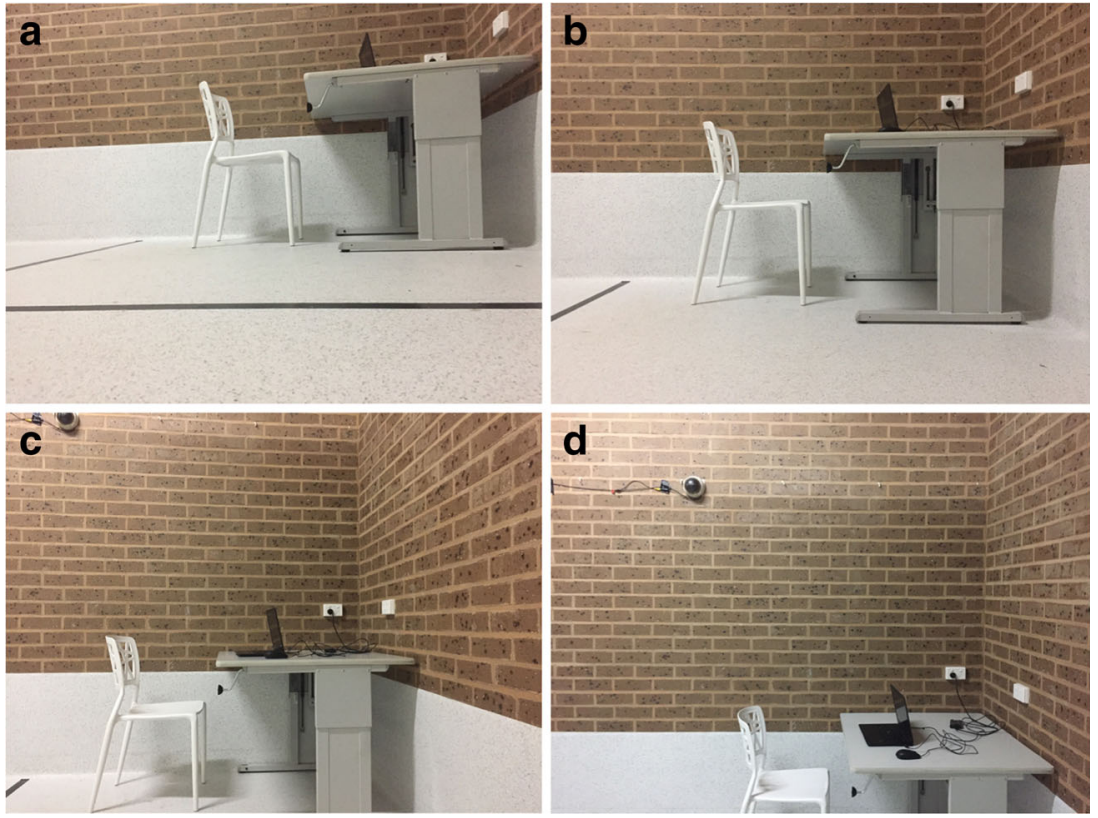

Fig. 3 A photographic example of the effect of visual perspective on vision. Above are four perspectives of an identical visual scene as viewed from 8 in. $(20.32 \mathrm{~cm})$ above the ground $(\mathbf{A}), 21$ in. $(53.34 \mathrm{~cm})$ above the ground $(\mathbf{B}), 34 \mathrm{in} .(86.36 \mathrm{~cm})$ above the ground $(\mathbf{C})$, and $66 \mathrm{in}$.

small differences in visual perception that made them better or worse at performing visually-dependent tasks, which then may have led to gradual, breed-specific changes in morphology and more exaggerated breed differences in visual perception (Fig. 5).

\section{Part 3 conclusions}

It is possible that morphological differences, such as nose length and the placement of the eyes, limit or aid certain dogs when perceiving their surroundings. We must clarify here that we are not suggesting that differences in morphology directly affect cognitive ability. We simply wish to highlight that current research suggests that, in certain cognitive tasks, some breeds and morphological types perform better than others. Additionally, in many studies assessing similar aspects of cognition (such as object permanence and gestural communication tasks discussed in the

$(167.64 \mathrm{~cm})$ above the ground $(\mathbf{D})$. The sizes were chosen to represent small, medium, and large dogs and humans, respectively, but assume identical "human-like" vision in all cases

introduction), variation is observed in findings. Given the diverse variation in canine morphology, it seems reasonable to assume that, due to selective pressures, some dogs may be better able to perceive certain cues during cognitive tasks. This may be due to differences in visual processing abilities or simply differences in size, height, and nose length. Sight-hounds, for example, often characterized partially by having relatively long snouts, may be quite adept at perceiving movement from far away and potentially may perceive the world very differently from pugs, which are much more flat-faced and therefore have increased binocular overlap. It will be important for future research to investigate whether these morphological differences are associated with variation in cognitive performance in visually-presented tasks. In the interim, because it is possible that morphological variation in the eye may result in differences in visual processing, thereby indirectly affecting performance outcomes in visual cognitive tasks, we
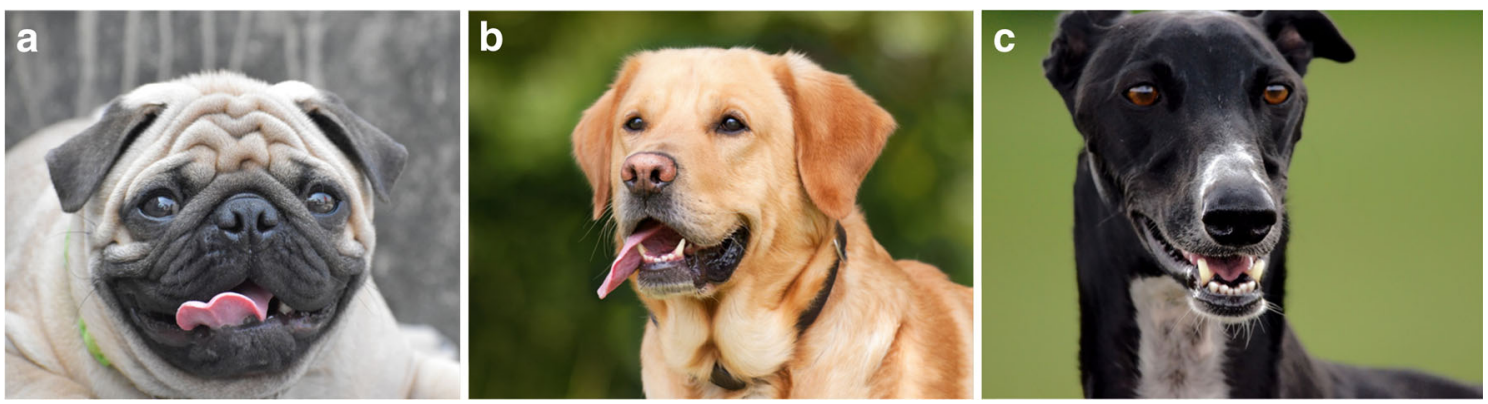

Fig. 4 Photographic representations of brachycephalic (A), mesocephalic (B), and dolichocephalic (C) dog breeds 


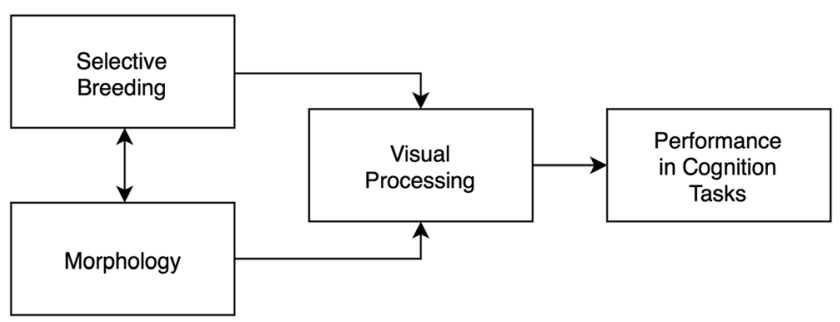

Fig. 5 Theoretical diagram of the proposed relationship between selective breeding, morphology, visual processing, and performance on cognitive tasks must ensure that any task used is not only relevant for assessing the cognitive component in question, but also that the methodology is appropriate for all subjects in the sample.

\section{Part 4: Avenues for future research}

In the last two decades, researchers have documented a variety of behaviors and abilities that make dogs a unique model for studying cognition, especially their social cognition.

Table 1. Key components discussed in this review, examples of specific questions that still need to be assessed, and whether any research has been conducted

\begin{tabular}{|c|c|c|}
\hline Topic & Questions & Has research been conducted? \\
\hline \multirow[t]{2}{*}{ Sensitivity to light } & $\begin{array}{l}\text { How does photo bleaching affect dog vision, and is there } \\
\text { a concern for researchers when assessing cognition } \\
\text { in conditions where the light has abruptly changed? }\end{array}$ & No research \\
\hline & $\begin{array}{l}\text { Do variations in the tapetal-area (either a complete lack } \\
\text { or partial lack) pose a concern for assessments such } \\
\text { as visual acuity? If so, how could these variations } \\
\text { affect the results of cognition studies? }\end{array}$ & No research \\
\hline Brightness discrimination & What is the brightness discrimination threshold in dogs? & Stone (1921); Pretterer et al. (2004) \\
\hline Visual acuity & $\begin{array}{l}\text { What is a typical dog's visual acuity? Are there breed } \\
\text { differences, or differences that are dependent on } \\
\text { facial morphology type (i.e. brachycephalic, } \\
\text { mesocephalic and dolichocephalic)? }\end{array}$ & $\begin{array}{l}\text { P. E. Miller and Murphy (1995); Murphy } \\
\text { et al. (1997); Tanaka, Ikeuchi, et al. (2000) }\end{array}$ \\
\hline Depth perception & $\begin{array}{l}\text { Does stereopsis increase in adult dogs? Does depth } \\
\text { perception vary based on facial morphology type? }\end{array}$ & Walk and Gibson (1961) \\
\hline \multirow[t]{2}{*}{ Color vision } & $\begin{array}{l}\text { Can dogs behaviorally discriminate between what } \\
\text { most humans see as red/green? }\end{array}$ & $\begin{array}{l}\text { Rosengren (1969); Tanaka, Watanabe, et al. } \\
\text { (2000); Kasparson et al. (2013) }\end{array}$ \\
\hline & $\begin{array}{l}\text { If dogs have the ability to perceive the UV spectrum, } \\
\text { what kind of stimuli should and should not be } \\
\text { presented them? }\end{array}$ & No research \\
\hline \multirow{3}{*}{$\begin{array}{l}\text { Visual discrimination and } \\
\text { form perception }\end{array}$} & \multirow[t]{3}{*}{ How do dogs visually process shapes and forms? } & Byosiere et al. (2017a) \\
\hline & & Byosiere et al. (2017a) \\
\hline & & Duke-Elder (1958); Karn and Munn (1932) \\
\hline Global vs. Local processing & $\begin{array}{l}\text { Are dogs in fact global processors? Are there additional } \\
\text { tests of precedence that can be conducted? }\end{array}$ & $\begin{array}{l}\text { Mongillo et al. (2016); Pitteri, Mongillo, } \\
\text { Carnier, and Marinelli (2014) }\end{array}$ \\
\hline Visual Perception & $\begin{array}{l}\text { Do dogs perceive the world differently than humans } \\
\text { and other animals, or is it relatively the same? }\end{array}$ & $\begin{array}{l}\text { Byosiere et al. (2016); Byosiere et al. (2017b); } \\
\text { Byosiere et al. (2017a) }\end{array}$ \\
\hline Face processing & $\begin{array}{l}\text { How do basic differences in vision and visual perception } \\
\text { affect how to interpret the findings of face processing } \\
\text { in dogs? How do differences in brightness thresholds, } \\
\text { and visual acuity affect these outcomes? Additionally, } \\
\text { do dogs process face-like outlines like human faces, } \\
\text { and does the size of the stimulus matter? }\end{array}$ & $\begin{array}{l}\text { Huber et al. (2013); Racca et al. (2010); } \\
\text { Racca et al. (2012); Nagasawa et al. (2011); } \\
\text { Autier-Dérian et al. (2013); Somppi et al. (2012) }\end{array}$ \\
\hline \multirow[t]{2}{*}{ Morphological variation } & $\begin{array}{l}\text { In addition to individual differences, and breed differences, } \\
\text { are there broader differences due to facial morphology } \\
\text { type? Research is needed to assess whether these kinds } \\
\text { of differences are potential confounds across studies on } \\
\text { canine cognition. If such differences do play a role, it is } \\
\text { important we begin to evaluate their extent and re-assess } \\
\text { certain cognitive tests. }\end{array}$ & $\begin{array}{l}\text { Evans and De Lahunta (2013); Kerswell et al. } \\
\text { (2010); Helton and Helton (2010); } \\
\text { Dorey et al. (2009); McGreevy et al. (2003); } \\
\text { Roberts et al. (2010); Gácsi et al. (2009) }\end{array}$ \\
\hline & $\begin{array}{l}\text { Are current cognitive assessments actually capable of } \\
\text { assessing dog cognition accurately? How do differences } \\
\text { in vision (within dogs and between humans and dogs) } \\
\text { affect the kinds of paradigms researchers use? }\end{array}$ & No research \\
\hline
\end{tabular}


However, it is surprising how much remains unknown about their visual-processing capacities. This is problematic, considering that the vast majority of cognition tasks utilize experimental paradigms relying heavily on visual processing. Wellestablished paradigms and protocols, found in human and primate comparative cognition literature, have been applied to comparative dog cognition studies, often without critical review. As human and primate visual capacities are quite comparable (Jacobs, 1996), many of these visual tasks were created with human visual-processing capabilities in mind. Studies that aim to adapt human/primate-designed visual tasks to dog cognition should, therefore, carefully consider the visual-processing skills of dogs, in order to avoid inappropriate experimental paradigms leading to inaccurate conclusions.

The findings observed in dog vision research are particularly relevant to researchers studying canine cognition, in which dogs are typically presented with visual scenes. Individual and breed variations on cognition tasks have yet to be fully assessed; many studies focus on studying a single breed, while others include mixed breed samples. While the latter may provide more generalized results, reflective of multiple dog breeds, there are clear differences in visual physiology between and within breeds. Before general conclusions about dog cognition can be made, therefore, we must assess whether or not "a dog, is a dog, is a dog," or are we, as cognition researchers, creating false conclusions by not assessing the effects morphological differences have on cognition?

Below we provide Table 1 as a quick guide to some of the key issues discussed in this review. The table includes examples, by no means exhaustive, of the questions that still need to be answered, as well as an indication of studies that have already been conducted on each topic. We also discuss more general recommendations for future studies on dog vision and cognition.

In general, there is a strong need to assess basic visual capabilities across a wider range of dogs. While a foundational understanding of the canine visual system is available, due to small sample sizes and/or the use of a limited number of breeds, it is not yet clear whether these findings are representative of all dogs. In any other species, small sample sizes are sufficient for foundational studies, because all members of a species can be assumed to be relatively homogeneous. This is not the case with domestic dogs, however, which provide an extreme example of just how flexible a species' phenotype can be. Until the extent to which these differences affect visual processing is known, researchers should perhaps attempt to assess cognitive performance in dogs using subjects with similar visual physiology. However, we also recommend that further investigation of dogs' visual processing skills is urgently needed. It is important that we continue to study dogs' unique cognitive abilities, but also that we assess the effects of additional factors, such as vision and/or morphology, on canine cognition.

More research is also needed on individual, breed, and morphological differences, and there is a strong need to better understand links between physiology, morphology, and cognition. Future studies should attempt to increase sample sizes as well as discern whether or not there are visual processing differences between mesocephalic, brachycephalic, and dolichocephalic dog breeds. Considering the unequalled variation in morphology between dogs of different breeds or breed types, they present a unique opportunity to better understand any effects these may have on vision. These studies should extend to visual acuity measures, as acuity has been estimated in only a few breeds. Considering the wider visual streak observed in longer nosed-breeds, it is possible that this characteristic enhances their ability to detect stimuli across a wider field of view at the cost of reducing the ability to discriminate fine details. Additionally, while some studies highlight a potential for color discrimination capabilities in dogs, since this is difficult to explain in neurophysiological terms, additional research should be conducted to ensure dogs are not using other cues on which to base their decisions. Considering dogs may have additional visual capacities to those most commonly tested, like the ability to see UV light, it is possible that their behavioral decisions are based on cues other than color. This requires further research.

Replication studies should be conducted to observe if there is consistency across findings. While many of the studies addressed above have observed consistent results, discrepancies in topics like visual perception, form perception, visual acuity, and color vision warrant further investigation. While many of these discrepancies may be due to differences in sample characteristics and methodology, a significant difficulty in assessing visual perception is the human-centric bias in experimental design. Often, behavioral oddities or performance faults in tasks are attributed to visual and cognitive inabilities. While an absence of evidence is not evidence of absence, such findings are rarely attributed to differences in sensory perception. This is particularly evident in the findings observed on geometric illusion susceptibility, and underlines the importance of careful experimental design. Due to the physiological differences underlying perceptual processing, researchers must keep in mind the differences underlying visual processing of dogs and the effects this may have on their cognition paradigms.

Finally, many of the studies described above have assessed vision in dogs by means of assessing their physiology. However, as noted in some instances, differences between physiological and behavioral measures have been observed. Considering it is important for any researcher utilizing a visual paradigm to understand the appropriate stimuli to use, future research should attempt to better understand why there might be differences between physiological evidence and behavioral 
observations; some experimental differences may simply reflect the type of dogs included in each study.

\section{References}

Aguirre, G. (1978). Retinal degenerations in the dog. I. Rod dysplasia. Experimental Eye Research, 26(3), 233-253.

Aguirre, G., \& Rubin, L. (1975). The electroretinogram in dogs with inherited cone degeneration. Investigative Ophthalmology \& Visual Science, 14(11), 840-847.

Araujo, J., Chan, A., Winka, L., Seymour, P., \& Milgram, N. (2004). Dose-specific effects of scopolamine on canine cognition: impairment of visuospatial memory, but not visuospatial discrimination. Psychopharmacology, 175(1), 92-98.

Arden, R., Bensky, M. K., \& Adams, M. J. (2016). A Review of Cognitive Abilities in Dogs, 1911 Through 2016: More Individual Differences, Please! Current Directions in Psychological Science, 25(5), 307-312.

Autier-Dérian, D., Deputte, B. L., Chalvet-Monfray, K., Coulon, M., \& Mounier, L. (2013). Visual discrimination of species in dogs (Canis familiaris). Animal Cognition, 16(4), 637-651. doi: https://doi.org/ 10.1007/s10071-013-0600-8

Baker, J. M., Morath, J., Rodzon, K. S., \& Jordan, K. E. (2012). A shared system of representation governing quantity discrimination in canids. Frontiers in Psychology, 3, 387

Bell, M. A., \& Fox, N. A. (1997). Individual differences in object permanence performance at 8 months: Locomotor experience and brain electrical activity. Developmental Psychobiology, 31(4), 287-297.

Bensky, M. K., Gosling, S. D., \& Sinn, D. L. (2013). The world from a dog's point of view: a review and synthesis of dog cognition research. Advances in the Study of Behaviour, 45, 209-406.

Bishop, P. O. (1987). Binocular vision. Adler's physiology of the eye: clinical application. St Louis: CV Mosby, 61989.

Bräuer, J., Kaminski, J., Riedel, J., Call, J., \& Tomasello, M. (2006). Making inferences about the location of hidden food: social dog, causal ape. Journal of Comparative Psychology, 120(1), 38.

Burman, O., McGowan, R., Mendl, M., Norling, Y., Paul, E., Rehn, T., \& Keeling, L. (2011). Using judgement bias to measure positive affective state in dogs. Applied Animal Behaviour Science, 132(3), 160168

Burns, M. S., Bellhorn, R. W., Impellizzeri, C. W., Aguirre, G. D., \& Laties, A. M. (1988). Development of hereditary tapetal degeneration in the beagle dog. Current Eye Research, 7(2), 103-114.

Byosiere, S. E., Feng, L. C., Chouinard, P. A., Howell, T. J., \& Bennett, P. C. (2017a). Relational concept learning in domestic dogs: Performance on a two-choice size discrimination task generalises to novel stimuli. Behavioural Processes, 145, 93-101.

Byosiere, S.-E., Feng, L. C., Rutter, N. J., Woodhead, J. K., Chouinard, P. A., Howell, T. J., \& Bennett, P. C. (2017b). Do dogs see the Ponzo illusion? Animal Behavior and Cognition, 44(4), 396-412. https:// dx.doi.org/10.26451/abc/.04.04.01.2017

Byosiere, S.-E., Feng, L. C., Woodhead, J. K., Rutter, N. J., Chouinard, P. A., Howell, T. J., \& Bennett, P. C. (2016). Visual perception in domestic dogs: susceptibility to the Ebbinghaus-Titchener and Delboeuf illusions. Animal cognition, 1-14. doi: https://doi.org/10. 1007/s10071-016-1067-1

Cavoto, K. K., \& Cook, R. G. (2001). Cognitive precedence for local information in hierarchical stimulus processing by pigeons. Journal of Experimental Psychology: Animal Behavior Processes, 27(1), 3.

Chouinard, P. A., Noulty, W. A., Sperandio, I., \& Landry, O. (2013). Global processing during the Müller-Lyer illusion is distinctively affected by the degree of autistic traits in the typical population. Experimental Brain Research, 230(2), 219-231.

Chouinard, P. A., Unwin, K. L., Landry, O., \& Sperandio, I. (2016). Susceptibility to Optical Illusions Varies as a Function of the Autism-Spectrum Quotient but not in Ways Predicted by LocalGlobal Biases. Journal of Autism and Developmental Disorders, 46(6), 2224-2239.

Collier-Baker, E., Davis, J. M., \& Suddendorf, T. (2004). Do dogs (Canis familiaris) understand invisible displacement? Journal of Comparative Psychology, 118(4), 421.

Craik, K. J. W. (1938). The effect of adaptation on differential brightness discrimination. The Journal of Physiology, 92(4), 406-421. doi: https://doi.org/10.1113/jphysiol.1938.sp003612

Dorey, N. R., Udell, M. A., \& Wynne, C. D. (2009). Breed differences in dogs sensitivity to human points: a meta-analysis. Behavioural Processes, 81(3), 409-415.

Dorey, N. R., Udell, M. A., \& Wynne, C. D. (2010). When do domestic dogs, Canis familiaris, start to understand human pointing? The role of ontogeny in the development of interspecies communication. Animal Behaviour, 79(1), 37-41.

Douglas, R., \& Jeffery, G. (2014). The spectral transmission of ocular media suggests ultraviolet sensitivity is widespread among mammals. Proceedings of the Royal Society of London B: Biological Sciences, 281(1780), 20132995.

Duke-Elder, S. (1958). System of Ophthalmology Vol. 1 The Eye in Evolution: Henry Kimpton.

Evans, H. E., \& De Lahunta, A. (2013). Miller's Anatomy of the Dog: Elsevier Health Sciences.

Feng, L. C., Chouinard, P. A., Howell, T. J., \& Bennett, P. C. (2016). Why do animals differ in their susceptibility to geometrical illusions? Psychonomic bulletin \& review, 1-15.

Fiset, S., Beaulieu, C., \& Landry, F. (2002). Duration of dogs' (Canis familiaris) working memory in search for disappearing objects. Animal Cognition, 6(1), 1-10. doi: https://doi.org/10.1007/s10071002-0157-4

Frank, H. (2011). Wolves, dogs, rearing and reinforcement: complex interactions underlying species differences in training and problem-solving performance. Behavior Genetics, 41(6), 830-839.

Gácsi, M., McGreevy, P., Kara, E., \& Miklósi, Á. (2009). Effects of selection for cooperation and attention in dogs. Behavioral and Brain Functions, 5(1), 31.

Gagnon, S., \& Dore, F. Y. (1992). Search behavior in various breeds of adult dogs (Canis familiaris): Object permanence and olfactory cues. Journal of Comparative Psychology, 106(1), 58-68. doi: https://doi. org/10.1037/0735-7036.106.1.58

Gagnon, S., \& Doré, F. Y. (1994). Cross-sectional study of object permanence in domestic puppies (Canis familiaris). Journal of Comparative Psychology, 108(3), 220.

Granar, M. I., Nilsson, B. R., \& Hamberg-Nyström, H. L. (2011). Normal color variations of the canine ocular fundus, a retrospective study in Swedish dogs. Acta Veterinaria Scandinavica, 53(1), 13.

Gregory, R. L. (2015). Eye and brain: The psychology of seeing: Princeton university press.

Griebel, U., \& Schmid, A. (1992). Color vision in the California sea lion (Zalophus californianus). Vision Research, 32(3), 477-482. doi: https://doi.org/10.1016/0042-6989(92)90239-F

Haber, R. N., \& Hershenson, M. (1973). The psychology of visual perception: Holt, Rinehart \& Winston.

Hare, B., Brown, M., Williamson, C., \& Tomasello, M. (2002). The domestication of social cognition in dogs. Science, 298(5598), 1634-1636.

Hare, B., \& Tomasello, M. (1999). Domestic dogs (Canis familiaris) use human and conspecific social cues to locate hidden food. Journal of Comparative Psychology, 113(2), 173. 
Hare, B., \& Tomasello, M. (2005). Human-like social skills in dogs? Trends in Cognitive Sciences, 9(9), 439-444. doi: https://doi.org/ 10.1016/j.tics.2005.07.003

Hart, B. L. (1995). Analysing breed and gender differences in behaviour. The domestic dog: Its evolution, behaviour and interactions with people, 65-77.

Healy, K., McNally, L., Ruxton, G. D., Cooper, N., \& Jackson, A. L. (2013). Metabolic rate and body size are linked with perception of temporal information. Animal Behaviour, 86(4), 685-696. doi: https://doi.org/10.1016/j.anbehav.2013.06.018

Helton, W. S., \& Helton, N. D. (2010). Physical size matters in the domestic dog's (Canis lupus familiaris) ability to use human pointing cues. Behavioural Processes, 85(1), 77-79.

Huber, L., Racca, A., Scaf, B., Virányi, Z., \& Range, F. (2013). Discrimination of familiar human faces in dogs (Canis familiaris). Learning and Motivation, 44(4), 258-269.

Jacobs, G. H. (1996). Primate photopigments and primate color vision. Proceedings of the National Academy of Sciences, 93(2), 577-581.

Jacobs, G. H., Deegan, J. F., Crognale, M. A., \& Fenwick, J. A. (1993). Photopigments of dogs and foxes and their implications for canid vision. Visual Neuroscience, 10(01), 173-180.

Kaminski, J. (2009). Dogs (Canis familiaris) are adapted to receive human communication Neurobiology of "Umwelt" (pp. 103-107): Springer.

Kaminski, J., Tempelmann, S., Call, J., \& Tomasello, M. (2009). Domestic dogs comprehend human communication with iconic signs. Developmental Science, 12(6), 831-837.

Kandel, E., \& Schwartz, J. (2000). Jessell. TM. Principles of Neural Science: New York: McGraw Hill.

Karn, H. W., \& Munn, N. L. (1932). Visual pattern discrimination in the dog. Pedagogical Seminary and Journal of Genetic Psychology, 40(2), 363-374.

Kasparson, A. A., Badridze, J., \& Maximov, V. V. (2013). Colour cues proved to be more informative for dogs than brightness. Proceedings of the Royal Society B: Biological Sciences, 280(1766). doi: https://doi.org/10.1098/rspb.2013.1356

Kemp, C., \& Jacobson, S. (1992). Rhodopsin levels in the central retinas of normal miniature poodles and those with progressive rod-cone degeneration. Experimental Eye Research, 54(6), 947-956.

Kerswell, K. J., Butler, K. L., Bennett, P., \& Hemsworth, P. H. (2010). The relationships between morphological features and social signalling behaviours in juvenile dogs: the effect of early experience with dogs of different morphotypes. Behavioural Processes, 85(1), 1-7.

Knill, D. C., \& Pouget, A. (2004). The Bayesian brain: the role of uncertainty in neural coding and computation. Trends in Neurosciences, 27(12), 712-719. doi:https://doi.org/10.1016/j.tins.2004.10.007

Koch, S., \& Rubin, L. (1972). Distribution of cones in retina of the normal dog. American Journal of Veterinary Research, 33(2), 361363.

Kraft, T. W., Schneeweis, D. M., \& Schnapf, J. L. (1993). Visual transduction in human rod photoreceptors. The Journal of Physiology, 464, 747-765.

Lamb, T. D., Collin, S. P., \& Pugh, E. N. (2007). Evolution of the vertebrate eye: opsins, photoreceptors, retina and eye cup. Nature Reviews Neuroscience, 8(12), 960-976.

Laycock, R., Crewther, S. G., \& Crewther, D. P. (2007). A role for the 'magnocellular advantage' in visual impairments in neurodevelopmental and psychiatric disorders. Neuroscience \& Biobehavioral Reviews, 31(3), 363-376. doi: https://doi.org/10. 1016/j.neubiorev.2006.10.003

Lesiuk, T., \& Braekevelt, C. (1983). Fine structure of the canine tapetum lucidum. Journal of Anatomy, 136(Pt 1), 157.

Masland, R. H., \& Martin, P. R. (2007). The unsolved mystery of vision. Current Biology, 17(15), R577-R582.
McGreevy, P., Grassi, T. D., \& Harman, A. M. (2003). A strong correlation exists between the distribution of retinal ganglion cells and nose length in the dog. Brain, Behavior and Evolution, 63(1), 13-22.

Miklösi, Á., Polgárdi, R., Topál, J., \& Csányi, V. (1998). Use of experimenter-given cues in dogs. Animal Cognition, 1(2), 113-121.

Miletto Petrazzini, M. E., Bisazza, A., \& Agrillo, C. (2016). Do domestic dogs (Canis lupus familiaris) perceive the Delboeuf illusion? Animal cognition, 1-8. doi: https://doi.org/10.1007/s10071-016-1066-2

Milgram, N. W., Head, E., Weiner, E., \& Thomas, E. (1994). Cognitive functions and aging in the dog: acquisition of nonspatial visual tasks. Behavioral Neuroscience, 108(1), 57.

Milgram, N. W., Head, E., Zicker, S. C., Ikeda-Douglas, C., Murphey, H., Muggenberg, B. A., ... Cotman, C. W. (2004). Long-term treatment with antioxidants and a program of behavioral enrichment reduces age-dependent impairment in discrimination and reversal learning in beagle dogs. Experimental Gerontology, 39(5), 753-765.

Miller, R. J. (1997). Pictorial Depth Cue Orientation Influences the Magnitude of Perceived Depth. Visual Arts Research, 23(1), 97-124.

Miller, H. C., Gipson, C. D., Vaughan, A., Rayburn-Reeves, R., \& Zentall, T. R. (2009). Object permanence in dogs: invisible displacement in a rotation task. Psychonomic Bulletin \& Review, 16(1), 150155.

Miller, P. E., \& Murphy, C. J. (1995). Vision in dogs. Journal of the American Veterinary Medical Association, 207, 1623-1634.

Mongillo, P., Pitteri, E., Sambugaro, P., Carnier, P., \& Marinelli, L. (2016). Global bias reliability in dogs (Canis familiaris). Animal Cognition, 1-9. doi: https://doi.org/10.1007/s10071-016-1044-8

Mowat, F. M., Petersen-Jones, S. M., Williamson, H., Williams, D. L., Luthert, P. J., Ali, R. R., \& Bainbridge, J. W. (2008). Topographical characterization of cone photoreceptors and the area centralis of the canine retina. Molecular Vision, 14, 2518-2527.

Murphy, C. J., Mutti, D. O., Zadnik, K., \& Ver Hoeve, J. (1997). Effect of optical defocus on visual acuity in dogs. American Journal of Veterinary Research, 58(4), 414-418.

Nagasawa, M., Murai, K., Mogi, K., \& Kikusui, T. (2011). Dogs can discriminate human smiling faces from blank expressions. Animal Cognition, 14(4), 525-533. doi: https://doi.org/10.1007/s10071011-0386-5

Navon, D. (1977). Forest before trees: The precedence of global features in visual perception. Cognitive Psychology, 9(3), 353-383.

Neitz, J., Geist, T., \& Jacobs, G. H. (1989). Color vision in the dog. Visual Neuroscience, 3(02), 119-125.

Nießner, C., Denzau, S., Malkemper, E. P., Gross, J. C., Burda, H., Winklhofer, M., \& Peichl, L. (2016). Cryptochrome 1 in retinal cone photoreceptors suggests a novel functional role in mammals. Scientific Reports, 6, 21848.

Ollivier, F., Samuelson, D., Brooks, D., Lewis, P., Kallberg, M., \& Komáromy, A. (2004). Comparative morphology of the tapetum lucidum (among selected species). Veterinary Ophthalmology, $7(1), 11-22$.

Parkes, J., Aguirre, G., Rockey, J., \& Liebman, P. (1982). Progressive rod-cone degeneration in the dog: characterization of the visual pigment. Investigative Ophthalmology \& Visual Science, 23(5), 674678.

Parry, H. (1953). Degenerations of the dog retina: I. Structure and development of the retina of the normal dog. The British Journal of Ophthalmology, 37(7), 385.

Peichl, L. (1992). Topography of ganglion cells in the dog and wolf retina. Journal of Comparative Neurology, 324(4), 603-620.

Petrazzini, M. E. M., \& Wynne, C. D. (2016). What counts for dogs (Canis lupus familiaris) in a quantity discrimination task? Behavioural Processes, 122, 90-97.

Pitteri, E., Mongillo, P., Carnier, P., \& Marinelli, L. (2014). Hierarchical stimulus processing by dogs (Canis familiaris). Animal Cognition, 17(4), 869-877. 
Pitteri, E., Mongillo, P., Carnier, P., Marinelli, L., \& Huber, L. (2014). Part-Based and Configural Processing of Owner's Face in Dogs. PLoS One, 9(9), e108176. doi: https://doi.org/10.1371/journal. pone. 0108176

Pongrácz, P., Miklósi, Á., Dóka, A., \& Csányi, V. (2003). Successful Application of Video-Projected Human Images for Signalling to Dogs. Ethology, 109(10), 809-821. doi: https://doi.org/10.1046/j. 0179-1613.2003.00923.x

Pongrácz, P., Ujvári, V., Faragó, T., Miklósi, Á., \& Péter, A. (2017). Do you see what I see? The difference between dog and human visual perception may affect the outcome of experiments. Behavioural Processes, 140, 53-60. doi:https://doi.org/10.1016/j.beproc.2017. 04.002

Pretterer, G., Bubna-Littitz, H., Windischbauer, G., Gabler, C., \& Griebel, U. (2004). Brightness discrimination in the dog. Journal of Vision, 4(3), 10-10. doi: https://doi.org/10.1167/4.3.10

Purves, D., Augustine, G., \& Fitzpatrick, D. (2001). Neuroscience. 2nd edition.: Sinauer Associates.

Racca, A., Amadei, E., Ligout, S., Guo, K., Meints, K., \& Mills, D. (2010). Discrimination of human and dog faces and inversion responses in domestic dogs (Canis familiaris). Animal Cognition, 13(3), 525-533.

Racca, A., Guo, K., Meints, K., \& Mills, D. S. (2012). Reading Faces: Differential Lateral Gaze Bias in Processing Canine and Human Facial Expressions in Dogs and 4-Year-Old Children. PLoS ONE, 7(4), e36076. doi: https://doi.org/10.1371/journal.pone.0036076

Range, F., Aust, U., Steurer, M., \& Huber, L. (2008). Visual categorization of natural stimuli by domestic dogs. Animal Cognition, 11(2), 339-347.

Roberts, T., McGreevy, P., \& Valenzuela, M. (2010). Human induced rotation and reorganization of the brain of domestic dogs. PLoS One, 5(7), e11946.

Rosengren, A. (1969). Experiments in colour discrimination in dogs: Societas pro fauna et flora Fennica.

Schmitt, V., Kröger, I., Zinner, D., Call, J., \& Fischer, J. (2013). Monkeys perform as well as apes and humans in a size discrimination task. Animal Cognition, 16(5), 829-838. doi: https://doi.org/10.1007/ s10071-013-0616-0

Scholtyssek, C., Kelber, A., \& Dehnhardt, G. (2008). Brightness discrimination in the harbor seal (Phoca vitulina). Vision Research, 48(1), 96-103. doi: https://doi.org/10.1016/j.visres.2007.10.012

Sherman, J. A., \& Chouinard, P. A. (2016). Attractive Contours of the Ebbinghaus Illusion. Perceptual \& Motor Skills, 122(1), 88-95.

Somppi, S., Törnqvist, H., Hänninen, L., Krause, C., \& Vainio, O. (2012). Dogs do look at images: eye tracking in canine cognition research. Animal Cognition, 15(2), 163-174. doi: https://doi.org/10.1007/ s10071-011-0442-1
Soproni, K., Miklósi, Á., Topál, J., \& Csányi, V. (2001). Comprehension of human communicative signs in pet dogs (Canis familiaris). Journal of Comparative Psychology, 115(2), 122.

Soproni, K., Miklósi, A., Topál, J., \& Csányi, V. (2002). Dogs'(Canis familaris) responsiveness to human pointing gestures. Journal of Comparative Psychology, 116(1), 27.

Stone, C. (1921). Notes on light discrimination in the dog. Journal of Comparative Psychology, 1(5), 413-431.

Tanaka, T., Ikeuchi, E., Mitani, S., Eguchi, Y., \& Uetake, K. (2000). Studies on the visual acuity of dogs using shape discrimination learning. Nihon Chikusan Gakkaiho, 71(6), 614-620.

Tanaka, T., Watanabe, T., Eguchi, Y., \& Yoshimoto, T. (2000). Color Discrimination in Dogs. Nihon Chikusan Gakkaiho, 71(3), 300304. doi: https://doi.org/10.2508/chikusan.71.300

Tapp, P. D., Siwak, C. T., Head, E., Cotman, C. W., Murphey, H., Muggenburg, B. A., ... Milgram, N. W. (2004). Concept abstraction in the aging dog: development of a protocol using successive discrimination and size concept tasks. Behavioural Brain Research, 153(1), 199-210. doi: https://doi.org/10.1016/j.bbr.2003.12.003

Tauzin, T., Csík, A., Kis, A., \& Topál, J. (2015). What or where? The meaning of referential human pointing for dogs (Canis familiaris). Journal of Comparative Psychology, 129(4), 334.

Udell, M. A., Dorey, N. R., \& Wynne, C. D. (2008). Wolves outperform dogs in following human social cues. Animal Behaviour, 76(6), 1767-1773.

Udell, M. A., \& Wynne, C. D. (2008). A review of domestic dogs' (canis familiaris) human-like behavior: or why behavior analysts should stop worrying and love their dogs. Journal of the Experimental Analysis of Behavior, 89(2), 247-261.

Virányi, Z., Gácsi, M., Kubinyi, E., Topál, J., Belényi, B., Ujfalussy, D., \& Miklósi, Á. (2008). Comprehension of human pointing gestures in young human-reared wolves (Canis lupus) and dogs (Canis familiaris). Animal Cognition, 11(3), 373-387.

Walk, R. D., \& Gibson, E. J. (1961). A comparative and analytical study of visual depth perception. Psychological Monographs: General and Applied, 75(15), 1.

Walls, G. L. (1942). The vertebrate eye and its adaptive radiation.

Ward, C., \& Smuts, B. B. (2007). Quantity-based judgments in the domestic dog (Canis lupus familiaris). Animal Cognition, 10(1), 71-80.

Wayne, R. K. (1986a). Cranial morphology of domestic and wild canids: the influence of development on morphological change. Evolution, 243-261.

Wayne, R. K. (1986b). Limb morphology of domestic and wild canids: the influence of development on morphologic change. Journal of Morphology, 187(3), 301-319.

Wayne, R. K., \& Ostrander, E. A. (2007). Lessons learned from the dog genome. Trends in Genetics, 23(11), 557-567.

Wynne, C. D., Udell, M. A., \& Lord, K. A. (2008). Ontogeny's impacts on human-dog communication. Animal Behaviour, 76(4), e1-e4. 